\title{
Doppler assessment of pulmonary artery pressure and extrapulmonary shunting in the acute phase of hyaline membrane disease
}

\author{
N J Evans, L N J Archer
}

\begin{abstract}
The natural history of pulmonary artery pressure and extrapulmonary shunting in acute hyaline membrane disease was studied by serial Doppler echocardiography in 57 preterm infants, 38 with, and 19 without, hyaline membrane disease. Pulmonary artery pressure was assessed non-invasively by its inverse relationship with the ratio of pulmonary artery Doppler time to peak velocity: right ventricular ejection time. The mean ratio was significantly lower in the infants with hyaline membrane disease. The mean ratio for each infant with hyaline membrane disease varied widely and did not correlate with criteria of maturity or severity of disease. Individual ratios correlated with arterial $\mathrm{pH}$. Between 60-80 hours after birth, 14 of 18 infants with hyaline membrane disease $(\mathbf{7 8 \%})$ and one of 19 without $(5 \%)$ had patent ductus arteriosus. Left to right and bidirectional shunting at ductal and atrial level were common; pure right to left shunting was uncommon. The mean ratio seen with bidirectional shunting was significantly lower than that seen with left to right shunting. Ratios and patterns of extra pulmonary shunting were similar when the fractional inspired oxygen $\left(\mathrm{F}_{1} \mathrm{O}_{2}\right)$ was $>0.9 \mathrm{com}-$ pared with when it was $<0.9$.

Pulmonary artery pressure is high during the acute phase of hyaline membrane disease but varies widely among infants. $A$ few infants have extrapulmonary right to left shunting, and these infants are difficult to detect clinically.
\end{abstract}

Early studies implicated persistent pulmonary hypertension that leads to right to left shunting of blood through extrapulmonary channels in both the pathogenesis of hyaline membrane disease and as a factor contributing to the subsequent hypoxaemia. ${ }^{1}$ Subsequent studies using direct $^{2}$ and indirect ${ }^{3}$ methods of assessment showed that raised pulmonary artery pressure was a consistent feature of severe hyaline membrane disease. Catheter studies, however, have shown that in most infants less than $10 \%$ of total right to left shunt occurs through extrapulmonary channels. ${ }^{4} 5$ Tolazoline used as a pulmonary vasodilator leads to improvement in oxygenation in some infants with severe hyaline membrane disease, ${ }^{6}$ but has a high incidence of serious complications. ${ }^{7}$ There is a need therefore to be able to diagnose those with appreciable right to left shunting through the ductus arteriosus and foramen ovale so that we can identify those who are most likely to respond to pulmonary vasodilators. ${ }^{8}$
Doppler echocardiography provides a noninvasive means by which to assess pulmonary artery pressure and extrapulmonary shunting. The ratio of pulmonary artery time to peak velocity: right ventricular ejection time (TPV:RVET) as measured from the Doppler waveform, has a close inverse correlation to pulmonary artery pressure. ${ }^{9}$ This method has two main advantages over the right ventricular systolic time intervals derived from $M$ mode echocardiography that were used in other indirect studies of pulmonary artery pressure in hyaline membrane disease. ${ }^{3}$ Firstly, in validation studies it has shown much closer correlation to pulmonary artery pressure. ${ }^{9}$ Secondly, Doppler echocardiography permits us to study blood flow patterns through the ductus arteriosus and foramen ovale at the same time as making an indirect assessment of pulmonary artery pressure. To our knowledge such Doppler studies have not previously been undertaken in hyaline membrane disease. The aim of this study therefore was to use these methods to compare the natural history of pulmonary artery pressure and extrapulmonary shunting in preterm infants with and without hyaline membrane disease. In this paper we looked specifically at the results during the acute phase of hyaline membrane disease; subsequent measurements taken during the recovery phase will be reported separately.

Subjects and methods

All infants were studied with an ATL Ultramark 4 scanner with range gated pulsed wave Doppler. Two dimensional imaging was done with a $7.5 \mathrm{MHz}$ transducer incorporating a $5 \mathrm{MHz}$ pulsed Doppler crystal.

The procedure for each study was as follows: the pulmonary artery was visualised from the parasternal long axis view. The Doppler sample volume was placed just distal to the pulmonary valve and the pulmonary artery velocity pattern was recorded. The pattern was frozen on screen and the time intervals measured using the incorporated Doppler measurement calipers; a print was then taken. TPV was measured as the time interval between the systolic Doppler waveform leaving the baseline and reaching its peak velocity. RVET was the time interval between the systolic waveform leaving its peak velocity and returning to the baseline. A mean of three systolic waveforms was taken. A second 'blind' observer repeated the measurements on 50 of the Doppler prints using a computer digitiser system. The correlation coefficient between 'on line' and 'blind' measurements was 0.92 .

The ductus arteriosus was then visualised 
from the high left parasternal ductal view. The Doppler sample volume was placed in the pulmonary end of the duct and the flow pattern recorded. The duct was classified: as 'closed' when it could not be visualised and no Doppler flow could be recorded; as 'restrictive' when it could not be visualised or there was a localised area of constriction but Doppler flow could be recorded; and as 'wide open' when it could be seen to be clearly patent throughout its course and Doppler flow was recorded.

Finally, the atrial septum was visualised from the subcostal four chamber view; the Doppler sample was placed in the foramen ovale and the flow pattern was recorded.

Fifty seven preterm infants were studied, 19 healthy infants without hyaline membrane disease and 38 infants with hyaline membrane disease. The healthy infants had a mean gestation of 31.8 weeks (range 28-34) and a mean birth weight of $1610 \mathrm{~g}$ (range 950-2050). The healthy infants had minimal or no extra oxygen requirements; two infants were initially placed in low concentrations of oxygen, but both were

Table 1 Criteria of severity of hyaline membrane disease in 38 affected infants, 36 of whom were treated with artificial ventilation

\begin{tabular}{lc}
\hline No with maximum $\mathrm{F}_{1} \mathrm{O}_{2}$ : & 5 \\
$<0.6$ & 16 \\
$0.6-0.9$ & 17 \\
$>0.9$ & $0 \cdot 8(0 \cdot 35-1 \cdot 0)$ \\
Mean (range) maximum $\mathrm{F}_{1} \mathrm{O}_{2}$ & $12 \cdot 8(5 \cdot 5-25 \cdot 5)$ \\
Mean (range) maximum mean airway & $\begin{array}{l}\text { pressure (cm } \mathrm{H}_{2} \mathrm{O} \text { ) } \\
\text { Mean (range) length of acute phase (hours) }\end{array}$ \\
$\begin{array}{l}\text { Median (range) length of time on } \\
\text { ventilator (hours) }\end{array}$ & $184(58-5880)$ \\
\hline
\end{tabular}

Table 2 Number of studies carried out in each age group. Some infants had more than one study in a particular group

\begin{tabular}{lll}
\hline $\begin{array}{l}\text { Age group } \\
\text { (hours) }\end{array}$ & $\begin{array}{l}\text { Infants with } \\
\text { hyaline membrane } \\
\text { disease }(n=38)\end{array}$ & $\begin{array}{l}\text { Infants without } \\
\text { hyaline membrane } \\
\text { disease }(n=19)\end{array}$ \\
\hline $0-6$ & 12 & 10 \\
$7-14$ & 11 & 8 \\
$15-24$ & 19 & 6 \\
$25-36$ & 18 & 13 \\
$37-48$ & 21 & 6 \\
$49-72$ & 20 & 18 \\
$73-96$ & 6 & 13 \\
$>96$ & 13 & 19 \\
\hline
\end{tabular}

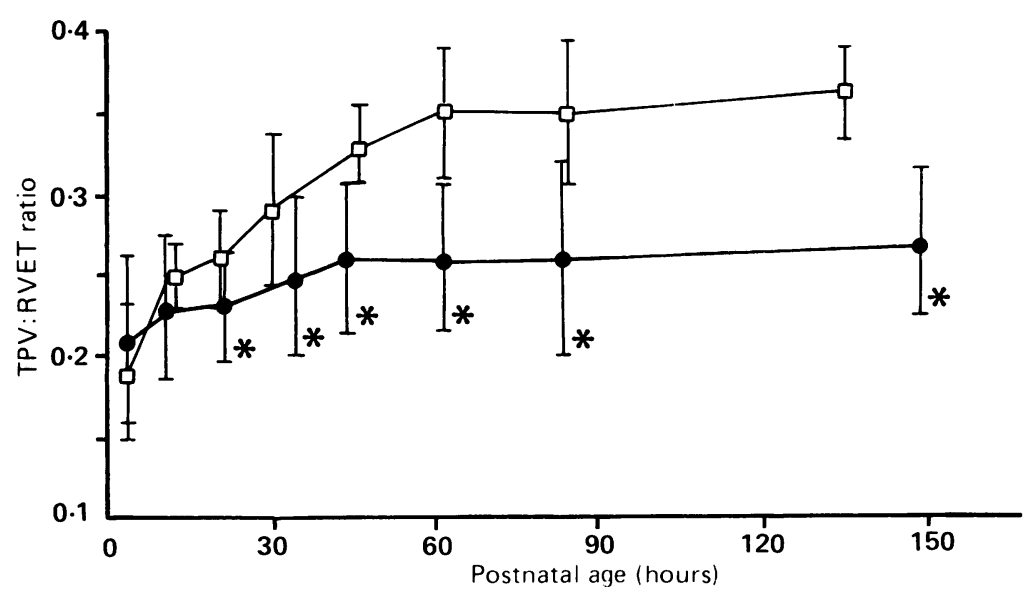

Figure 1 Comparison of the change in mean $(S D)$ time to peak velocity: right ventricular ejection time (TPV:RVET) ratio in preterm infants with (solid circles) and without (open squares) hyaline membrane disease. ${ }^{*}=\mathrm{p}<0.05$. breathing air by 24 hours. The healthy group of infants were studied initially during the first 12 hours after birth and then at 24 hour intervals until a steady state TPV:RVET ratio was achieved.

The infants with hyaline membrane disease had a mean gestation of 30.5 weeks (range 2637 ) and a mean birth weight of $1570 \mathrm{~g}$ (range 580-2960). The differences in birth weight and gestation between the two groups were not significant. The criteria for the severity of respiratory disease are shown in table 1 . The infants with hyaline membrane disease were studied as soon as possible after birth and then at least at 24 hour intervals. At the time of each study, records were kept of oxygen treatment, ventilator settings, most recent $\mathrm{pH}$ and blood gas measurements, and directly measured blood pressure. The results comprise those measurements made during the acute phase of hyaline membrane disease, which was defined as the time until the fractional inspired oxygen $\left(\mathrm{F}_{\mathrm{I}} \mathrm{O}_{2}\right)$ had peaked and returned to below 0.5 .

Statistical analysis was by Student's unpaired $t$ test, $\chi^{2}$ test, and linear regression analysis. A $p$ value of $<0.05$ was accepted as significant. The study was approved by the Central Oxford Research ethics committee.

\section{Results}

TPV:RVET RATIO

To compare changes in TPV:RVET ratio in infants with and without hyaline membrane disease, the studies were grouped by postnatal age. The number of studies in each age group is shown in table 2 . In fig 1 the mean (1 SD) ratio has been plotted at the mean measurement time. In the infants without hyaline membrane disease, the mean ratio rose over the first 72 hours of life, and then remained constant. In contrast, the mean ratio in the acute phase of hyaline membrane disease rose slightly during the first 24 hours, with only a small increase after that time. Within the first six hours, the mean (SD) TPV:RVET ratio was $0.21(0.05)$ in the infants with hyaline membrane disease and $0.195(0.04)$ in those without; this difference was not significant. After 15 hours in all groups the mean ratio was significantly less in the infants with hyaline membrane disease. By 73 to 96 hours, the mean ratio was $0.26(0.06)$ in those with hyaline membrane disease compared with $0.35(0.045)$ in those without $(p<0.01)$. There was a wide variation in ratios among individual infants in the group with hyaline membrane disease. Examples taken from the lower, middle, and upper part of the range are shown in fig 2. To measure this variation, the mean TPV:RVET ratio was calculated for the acute phase in each infant: this ranged from 0.175 to 0.34 with an overall mean of 0.25 . The mean ratio during the acute phase of hyaline membrane disease in each infant showed no significant correlation with gestation, birth weight, maximum $\mathrm{F}_{\mathrm{I}} \mathrm{O}_{2}$, or the length of the acute phase. Individual ratio measurements also showed no significant correlation with $\mathrm{F}_{\mathrm{I}} \mathrm{O}_{2}$, peak inspiratory pressure, or mean airway pressure at the time of the study, but did show a 


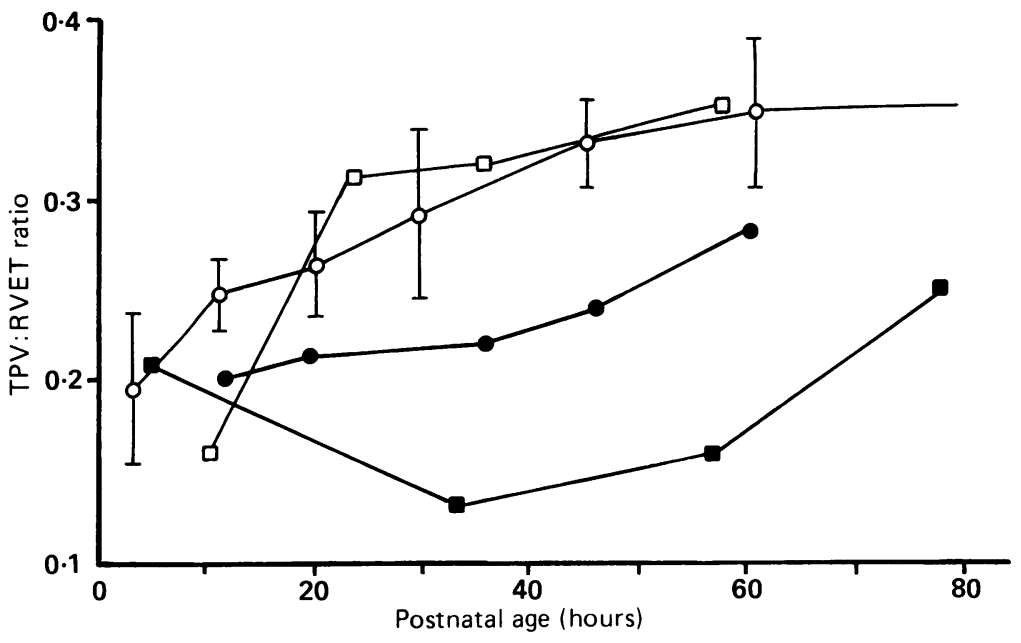

Figure 2 Examples of longitudinal change in time to peak velocity: right ventricular ejection time (TPV:RVET) ratios in three infants with hyaline membrane disease. Gestational ages and maximum inspired oxygen concentrations were: 34 weeks, $80 \%$ (open squares); 29 weeks, $100 \%$ (solid circles); and 36 weeks, $100 \%$ (solid squares). For comparison, changes in mean (SD) TPV:RVET ratio for healthy preterm infants are shown (open circles).

weak but significant correlation with the most recent arterial $\mathrm{pH}(\mathrm{r}=0.24, \mathrm{p}<0.01)$.

\section{DUCTUS ARTERIOSUS}

The incidence of ductal closure with age is shown in the two groups of infants in table 3. Within the first 20 hours only one duct, in an infant with hyaline membrane disease, was found to be closed. In the infants without hyaline membrane disease, ductal closure was complete in 18 of 19 studies (95\%) by $60-79$ hours. In contrast, in the infants with hyaline

Table 3 Number (\%) of studies in each age group that showed a closed ductus arteriosus. No infant had more than one study in each group

\begin{tabular}{llcl}
\hline $\begin{array}{l}\text { Age } \\
\text { group } \\
\text { (hours) }\end{array}$ & $\begin{array}{l}\text { Infants with } \\
\text { hyaline membrane } \\
\text { disease }\end{array}$ & $\begin{array}{l}\text { Infants without } \\
\text { hyaline membrane } \\
\text { disease }\end{array}$ & $p$ Value \\
\hline $0-19$ & $1 / 26(4)$ & $0 / 17$ & Not applicable \\
$20-39$ & $6 / 27(22)$ & $10 / 19(53)$ & 0.03 \\
$40-59$ & $5 / 27(19)$ & $15 / 17(88)$ & $<0.001$ \\
$60-79$ & $4 / 18(22)$ & $18 / 19(95)$ & $<0.001$ \\
\hline
\end{tabular}

Table 4 Number (\%) of studies showing each pattern of Doppler flow through the ductus arteriosus in each age group

Age group (hours) Left to right Bidirectional Right to left

$0-19(\mathrm{n}=25) \quad 14(56) \quad 10(40) \quad 1(4)$

$\begin{array}{rrrr}0-19(\mathrm{n}=25) & 14(56) & 10(40) & 1(4) \\ 20-39(\mathrm{n}=21) & 12(57) & 8(38) & 1(5)\end{array}$

$\quad 15(68)$

$60-79(n=14) \quad 12(85) \quad 2(14) \quad 0$

membrane disease, only four of 18 studies $(22 \%)$ showed a closed duct within this time period $(p<0.01)$. In the infants with hyaline membrane disease the patent ducts tended to get smaller with age; 15 of 26 studies in the first 19 hours showed a wide open duct (58\%) compared with three of 18 studies between 60-79 hours $(17 \%)$.

Three Doppler velocity time patterns of flow through the ductus arteriosus were seen (fig 3): left to right, in which flow was left to right through the cardiac cycle; an early systolic cessation of flow as seen in fig 3 was often a feature of this pattern; bidirectional, in which early systolic flow was right to left with a variable degree of late systolic and pandiastolic flow was from left to right; and right to left, in which flow was in this direction through the cardiac cycle. In the infants without hyaline membrane disease, the flow was left to right in all but five of the nine studies done in the first eight hours, when it was bidirectional. Within the first 19 hours in the infants with hyaline membrane disease flow was left to right in $56 \%$ of studies, with just one study (4\%) showing right to left flow; in the remainder $(40 \%)$ the flow was bidirectional (table 4). By 60 to 79 hours, $85 \%$ showed left to right flow with just two studies showing bidirectional flow. Only two of the 120 studies in the infants with hyaline membrane disease showed right to left flow.

In studies in which the duct was closed the TPV:RVET varied between $0 \cdot 16$ and $0 \cdot 40$ (mean 0.28). Mean (SD) TPV:RVET ratio in studies with left to right ductal shunt was 0.25 $(0.045)$, which is significantly higher than those with bidirectional shunts $(0.225 \quad(0.045)$, $\mathrm{p}<0.001$ ), and those with right to left shunts $(0.215(0.021), p<0.005)$. In the studies with

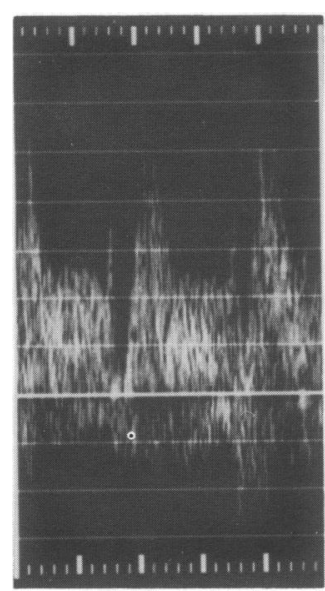

Left to right

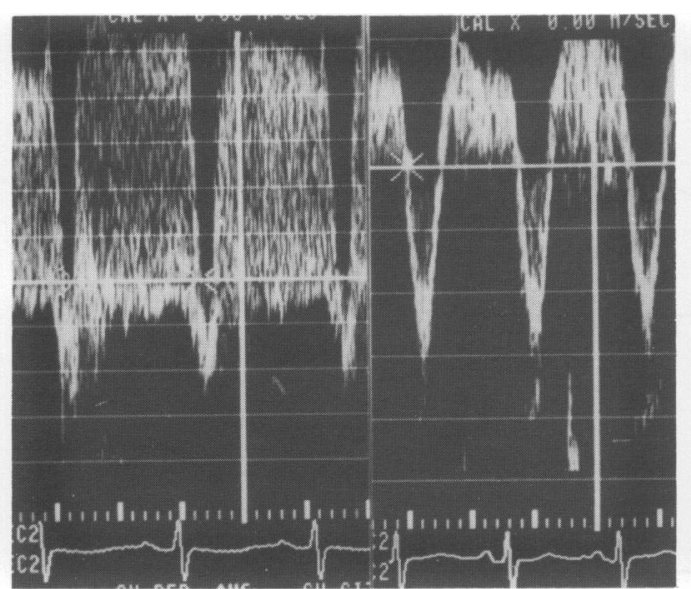

Bidirectional

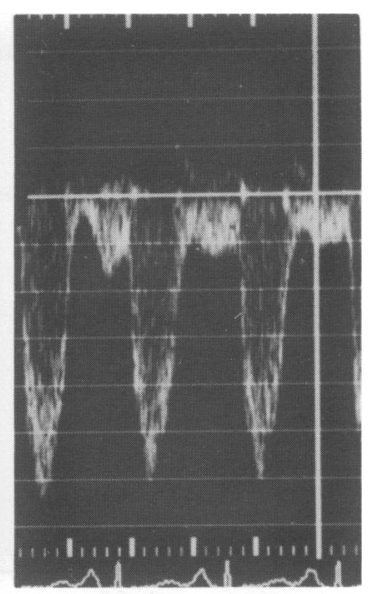

Right to left

Figure 3 Doppler flow patterns through the ductus arteriorsus. Positive deflection represents left to right flow and negative deflection right to left flow. In the bidirectional group there are two examples illustrating an increasing proportion of the cardiac cycle occupied by right to left shunting. 

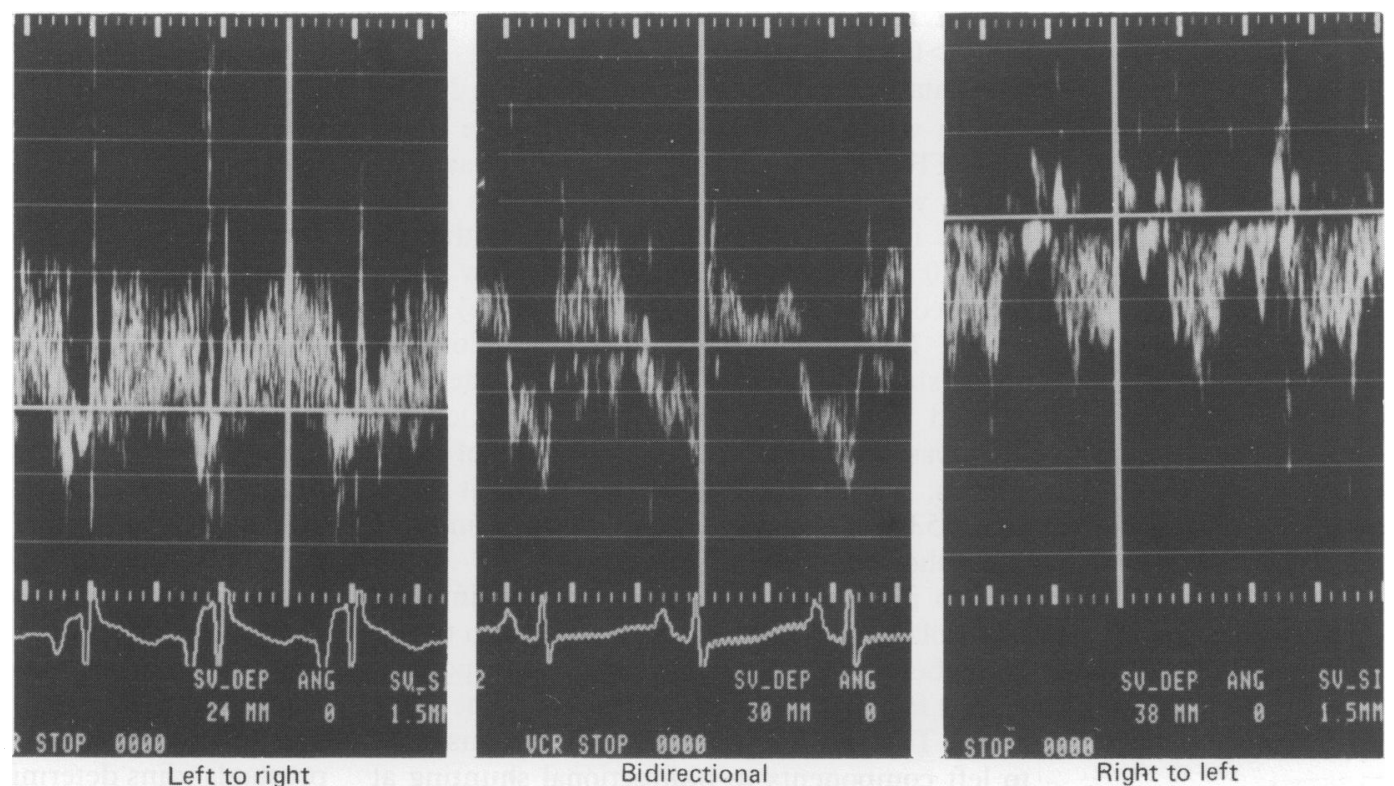

Figure 4 Interatrial Doppler flow patterns. Positive deflection represents left to right flow and negative deflections right to left flow.

bidirectional shunting there were considerable variations in the length of right to left shunting within the cardiac cycle. This was measured with the incorporated Doppler measurement calipers as the time between which the right to left Doppler flow left and returned to the baseline. This time was then expressed as a ratio to the RVET (right-left:RVET ratio), to standardise for different heart rates. In the studies with bidirectional ductal shunting, the rightleft:RVET ratio ranged from $0 \cdot 125$ to $1 \cdot 0$ (mean $0.52)$. The right-left:RVET ratio correlated significantly with the TPV:RVET ratio $(r=-0.55$, $p<0.0001$ ) and $\mathrm{F}_{\mathrm{I}} \mathrm{O}_{2}$ at the time of study ( $\mathrm{r}=$ $-0.53, p<0.0001)$ but no correlation was found with mean systemic blood pressure. Of ducts with bidirectional right to left flow, $97 \%$ were classified as 'wide open' compared with only $17 \%$ of these with left to right flow.

\section{ATRIAL SHUNTING}

For practical reasons it was not possible to get good quality Doppler studies of interatrial flow in all cases; the number of studies of interatrial flow are therefore less than for ductal flow. Some degree of incompetence of the foramen ovale was detected in all infants whose studies were satisfactory. Some bidirectional flow was seen in all studies. For analysis the studies were divided into three patterns (fig 4). (1) Left to right: maximum left to right flow was seen in ventricular systole and early diastole with cessation of flow or small right to left flow in mid to late diastole. (2) Bidirectional: right to left flow extended from late diastole into early systole with left to right flow in late systole and early diastole. (3) Right to left: the right to left flow dominated throughout most of the cardiac cycle.

Data on atrial shunting was obtained in only seven of the healthy infants because of incompleteness of the early studies. In all studies in these infants the flow was predominantly left to right. Within the first 20 hours in the infants with hyaline membrane disease four studies (31\%) showed bidirectional flow, one study showed right to left flow ( $8 \%$ ), and the remaining eight $(62 \%)$ showed left to right flow (table $5)$. The percentage showing bidirectional flow rose to $61 \%(n=11)$ between 20 to 39 hours and fell to $25 \%(n=2)$ between 60 and 79 hours. Just two studies showed predominantly right to left flow.

Mean (SD) TPV:RVET ratio in the studies with left to right flow was $0.27(0.05)$; this was significantly higher than those with bidirectional flow $0.23(0.04), \mathrm{p}<0.001$, and those with right to left flow, $0.19(0.035), \mathrm{p}<0.05$.

The matching of atrial and ductal patterns of shunting in studies where both were satisfactorily recorded is shown in table 6 . In studies where ductal shunting was left to right or bidirectional, 21 of 34 studies (62\%) showed identical patterns of atrial shunting. In the one ductal study with right to left shunting where the atrial shunt was also recorded the atrial flow was also right to left.

Table 5 Number (\%) of studies showing each pattern of Doppler flow through the foramen ovale in each age group

\begin{tabular}{rccl}
\hline Age group (hours) & Left to right & Bidirectional & Right to left \\
\hline $0-19(n=13)$ & $8(62)$ & $4(31)$ & $1(8)$ \\
$20-39(n=18)$ & $7(39)$ & $11(61)$ & 0 \\
$40-59(n=17)$ & $8(47)$ & $8(47)$ & $1(6)$ \\
$60-79(n=8)$ & $6(75)$ & $2(25)$ & 0 \\
\hline
\end{tabular}

Table 6 Matching of patterns of ductal and interatrial Doppler flow. Data are expressed as number (\%) of studies

\begin{tabular}{llll}
\hline & \multicolumn{3}{c}{ Direction of interatrial flow } \\
\cline { 2 - 4 } & Left to right & Bidirectional & Right to left \\
\hline $\begin{array}{c}\text { Direction of ductal flow: } \\
\text { Left to right } \\
(\mathrm{n}=34)\end{array}$ & $21(62)$ & $13(38)$ & 0 \\
$\begin{array}{c}\text { Bidirectional } \\
(\mathrm{n}=21) \\
\begin{array}{c}\text { Right to left } \\
(\mathrm{n}=1)\end{array}\end{array}$ & $7(33)$ & $13(62)$ & $1(5)$ \\
\hline
\end{tabular}


SEVERE HYALINE MEMBRANE DISEASE

$\left(\mathrm{F}_{\mathrm{I}} \mathrm{O}_{2}>0.9\right)$

The data were analysed separately in the $28 \mathrm{stu}$ dies in which the $\mathrm{F}_{1} \mathrm{O}_{2}$ was $>0.9$. The mean (SD) TPV:RVET ratio in this group was 0.25 $(0.04)$, which was identical to the mean in the studies in which the $\mathrm{F}_{\mathrm{I}} \mathrm{O}_{2}$ was $<0.9$-that is, $0.25(0.05)$. Ductal patency and flow were recorded in all 28 studies: five $(18 \%)$ were closed, 12 (43\%) showed left to right flow, 10 (36\%) showed bidirectional flow, and one (4\%) showed right to left flow. Interatrial Doppler flow was satisfactorily recorded in 15 of these studies: six (40\%) showed left to right flow, eight $(53 \%)$ showed bidirectional flow, and one (7\%) showed right to left flow.

Two infants in this group received intravenous tolazoline; both had been studied in the 12 hours before receiving the drug. One responded with a fall in $\mathrm{F}_{\mathrm{I}} \mathrm{O}_{2}$ from 1.0 to 0.8 . The most recent TPV:RVET was $0 \cdot 13$ with obvious right to left components to bidirectional shunting at ductal and atrial level. The other did not respond. The most recent TPV:RVET was 0.27 with left to right shunting at ductal and atrial level. Neither infant was studied at the time that the drug was given.

\section{Discussion}

Our results show that indirectly measured pulmonary artery pressure remains significantly higher in preterm infants during the acute phase of hyaline membrane disease than in those with no respiratory problems. This is consistent with the findings of previous authors who used both direct and indirect methods to assess pulmonary artery pressure in infants with severe hyaline membrane disease. ${ }^{2}{ }^{3}$ Moss et al using direct measurements within $\mathbf{4 8}$ hours of birth, found a mean pulmonary artery pressure of $45 \mathrm{~mm} \mathrm{Hg}$ in infants with hyaline membrane disease compared with $32 \mathrm{~mm} \mathrm{Hg}$ in those without ${ }^{2}$; in those with hyaline membrane disease pressures varied between 28 and $58 \mathrm{~mm} \mathrm{Hg}$. In our study the suggested pulmonary artery pressure also showed a wide degree of variation among infants, with the lowest pressures well within the normal range. Unlike Halliday et $a l^{3}{ }^{3}$ however, we found no correlations between indirectly assessed pulmonary artery pressure and indices of infant maturity or disease severity. It would therefore be difficult to predict those with the highest pulmonary vascular resistance solely from clinical variables.

Many factors influence pulmonary vascular resistance. ${ }^{11}$ For example, hypoxaemia and acidosis are both potent vasoconstrictors. ${ }^{12}$ The $\mathrm{pH}$ and blood gases were not measured at the time of the study, but were the most recent measurements. This, combined with the frequent rapid fluctuation in oxygen tension, means that we are not able to comment on the influence of hypoxia. There was however, no correlation with $\mathrm{F}_{\mathrm{I}} \mathrm{O}_{2}$ at the time of study. $\mathrm{pH}$ changes less rapidly, and there was a weak but significant correlation with TPV:RVET ratio. Mechanical factors have also been suggested as a cause of increased pulmonary vascular resis- tance. High positive end expiratory pressures increase both extra pulmonary shunting in immature animals ${ }^{13}$ and hypoxia in human newborns. ${ }^{14}$. End expiratory pressures of more than $5 \mathrm{~cm} \mathrm{H}_{2} \mathrm{O}$ were not used in this study, but there was no association between TPV:RVET and mean airway or peak airway pressure.

Prostaglandins seem to play an important part in the changes in pulmonary vascular resistance that occur after birth. As gestation advances and immediately after birth the balance of vasoconstrictor and vasodilator prostaglandins shifts towards the vasodilators. ${ }^{11}$ Studies of circulating prostaglandins and their metabolites in hyaline membrane disease have been contradictory. One study showed an increase in the constrictor prostaglandin $\mathrm{F}_{2 \alpha}, 15$ another correlated higher metabolic concentrations of the dilator prostacyclin with increasing severity of respiratory disease. ${ }^{16}$ It may be that the balance between dilator and constrictor prostaglandins determines the variable pulmonary artery pressure observed in the infants in this study.

In healthy preterm infants the ductus arteriosus usually closes within the first three days of life. ${ }^{17}$ This study shows that $80 \%$ of infants with hyaline membrane disease have patent ducts throughout the acute phase of the illness. Thus it seems that respiratory disease is an important factor in the development of prolonged ductal patency. Hypoxia, and possibly increased levels of ductal dilatory prostaglandins, ${ }^{18}$ may combine with reduced ductal muscle mass and reduced oxygen induced vasoconstriction, ${ }^{19}$ to maintain patency in these preterm infants. This study did not attempt to correlate ductal patency with physical signs. Anecdotally, however, we have observed that murmurs were present in only a few cases and were usually associated with high velocity turbulent left to right shunts, often through a quite constricted duct.

Bidirectional flow through the ductus is seen when pulmonary artery pressure is slightly less than aortic. ${ }^{20}$ The early systolic right to left flow is probably a reflection of two factors. Firstly, that proximity to the heart means that pressure rises earlier in systole at the pulmonary than at the aortic end of the duct. Secondly, the fact that in pulmonary hypertension systolic pressure may rise relatively more than diastolic, producing a peak pressure briefly in excess of aortic peak pressure. ${ }^{20}$ This study has shown that as pulmonary artery pressure rises so the duration of right to left flow increases. When pulmonary artery pressure is less than aortic throughout the cardiac cycle, so the flow will be left to right. This pattern was seen in most of the studies throughout the acute phase of hyaline membrane disease; mean TPV:RVET was significantly higher than in those with bidirectional flow. There was a considerable degree of overlap suggesting that pulmonary artery pressure may not be the sole determinant of flow pattern. Relative aortic pressure is important as well as the size of the duct and resistance to flow; almost all the ducts with bidirectional flow were widely patent. High pulmonary pressure is not always associated with a patent duct, however. 
Low TPV:RVETs were seen when the ducts were closed.

Pressure differences between the atria through the cardiac cycle are complex and have been well documented in children with atrial septal defects. ${ }^{21}$ In these children maximum left to right shunting occurs in late ventricular systole and early diastole, and in almost all cases there are two periods of minimal or right to left flow: firstly, after the atrioventricular valve has opened in mid to late diastole and, secondly, at the onset of ventricular contraction in early systole. The Doppler patterns correlate closely with this, though the right to left flow in early systole was less commonly seen. With higher right sided pressures, the right to left flow in late diastole and early systole merged to produce a more bidirectional pattern. We confirmed that a small amount of right to left flow occurs across atrial communications even when the right sided pressures are normal.

In this study, we have looked at patterns of flow and did not attempt to calculate extra pulmonary right to left shunt size or its contribution to systemic hypoxia. This study has shown, however, that even when the $\mathrm{F}_{\mathrm{I}} \mathrm{O}_{2}$ was more than $0.9,60 \%$ of examinations showed either no flow or left to right flow through the duct, and $40 \%$ showed left to right flow at atrial level. In the remainder the right to left flow occupied only a small part of the cardiac cycle. We therefore confirm previous studies that showed that the main site of right to left shunting in most infants with hyaline membrane disease is probably intrapulmonary. ${ }^{45} \mathrm{~A}$ small proportion of infants show appreciable extra pulmonary right to left shunting, particularly during the first $\mathbf{4 8}$ hours, and it is likely that these are the infants who will produce the best response to pulmonary vasodilators. ${ }^{8}$ Identifying these infants using clinical variables is not possible.

We hope that the methods described in this study will identify those that are most likely to respond to pulmonary vasodilators and might also make further investigations of the haemodynamic effects of these drugs in hyaline membrane disease easier.
We thank Dr A Wilkinson and Dr P Hope for their help and encouragement and for allowing us to study infants under their care. We also thank Claire Deeley for typing the manuscript.

1 Chu J, Clements JA, Colton EK, et al. Neonatal pulmonary ischemia. Pediatrics 1967;40:709-66.

2 Moss AJ, Emmanouilides GC, Rettori O, Higashino SM, Adams FH. Postnatal circulatory and metabolic adjustments in normal and distressed premature infants. Biol Neonate 1965;8:177-97.

3 Halliday HL, Hirschfeld S, Riggs T, et al. Respiratory distress syndrome echocardiographic assessment of cardiovastress syndrome echocardiographic assessment of cardiovas-
cular function and pulmonary vascular resistance. Pediatrics $1977 ; 60: 444-9$.

4 Roberton NRC, Dahlenburg GW. Ductus arteriosus shunts in respiratory distress syndrome. Pediatr Res 1969;3:149 59.

5 Murdock AI, Kidd BSL, Llewellyn MA, et al. Intrapulmonary venous admixture in the respiratory distress syndrome. Biol Neonate 1970;15:1-7.

6 McIntosh N, Walters RO. Effect of tolazoline in severe hyaline membrane disease. Arch Dis Child 1979;54:105-10.

7 Stevenson DK, Kasting DS, Darnall RA, et al. Refractory hypoxemia associated with neonatal pulmonary disease: the use and limitations of tolazoline. $\mathcal{F}$ Pediatr 1979;95: 595-9.

8 Johnson GL, Cunningham MD, Desai NS, Cottril CM, Noonan JA. Echocardiography in hypoxemic neonatal pulmonary disease. $\mathcal{F}$ Pediatr 1980;96:716-20.

9 Kitabatake A, Inoue M, Asao M, et al. Non-invasive evaluation of pulmonary hypertension by a pulsed Doppler techtion of pulmonary hypertension by a

10 Hirschfeld S, Meyer R, Swartz D, et al. The echocardiographic assessment of pulmonary artery pressure and pul-

11 Lyrene RK, Phillips JB. Control of pulmonary vascular resistance in the fetus and newborn. Clin Perinatol 1984;2:551-64.

12 Rudolph AM, Yuan S. Response of the pulmonary vasculature to hypoxia and $\mathrm{H}^{+}$ion concentration changes. $\mathcal{F}$ Clin Invest 1966;45:399-411

13 Egan EA, Hessler JR. Positive end expiratory pressure (PEEP) and right to left shunting in immature goats. Pediatr Res 1976;10:932-7.

14 Nelson RM, Egan EA, Fitzman DV. Increased hypoxaemia in neonates secondary to the use of continuous positive airway pressure. 7 Pediatr 1977;91:87-91.

15 Friedman Z, Demers LM. Essential fatty acids, prostaglandins and respiratory distress syndrome of the newborn. Pediatrics 1978;61:341-7.

16 Kaapa P, Koivisto M, Viinikka L, et al. Increased plasma immunoreactive 6-keto prostaglandin $\mathrm{F}$ levels in newborns with idiopathic respiratory distress syndrome. Pediatr Res with idiopathic

17 Evans NJ, Archer N. Postnatal circulatory adaptation in healthy term and preterm neonates. Arch Dis Child 1990; 65:24-6.

18 Hammerman C, Strates E, Valaitis S. The silent ductus: its precursors and its aftermath. Pediatr Cardiol 1986;7:121-7.

19 Murphy DM, Heyman MA, Rudolph AM, Melmon KL. Constriction of the ductus arteriosus. Pediatr Res 1972;6:231-8.

20 Houston AB, Lim MK, Doia WB. Doppler flow characteristics in the assessment of pulmonary artery pressure in ductus arteriosus. $B r$ Heart $\mathcal{f}$ 1989;62:284-90.

21 Levin AR, Spach MS, Bioneau JP, et al. Atrial pressure flow dynamics in atrial septal defects. Circulation 1968;37: 476-88. 